\title{
A SEGUNDA TELA E AS CONVERSAÇÕES NAS REDES SOCIAIS \\ ANÁLISE DO COMPORTAMENTO DAS TVS PÚBLICAS DE MINAS GERAIS
}

SORAYA FERREIRA UNIVERSIDADE FEDERAL DE JUIZ DE FORA JUIZ DE FORA, MINAS GERAIS, BRASIL E-MAIL: SOVFERREIRA@GMAIL.COM

ISABELA NORTON UNIVERSIDADE FEDERAL DE JUIZ DE FORA JUIZ DE FORA, MINAS GERAIS, BRASIL E-MAIL: NORTONISABELA@GMAIL.COM

HTTP://DX.DOI.ORG/10.5902/2316882X22190 
A SEGUNDA TELA E AS CONVERSAÇÕES NAS REDES SOCIAIS: ANÁLISE DO COMPORTAMENTO DAS TVS PÚBLICAS DE MINAS GERAIS

Resumo: Queremos entender como se dá a dinâmica dos processos comunicacionais e de fluição por parte das emissoras públicas e dos seus usuários. Através de análises (em 2014 e 2016) interpretamos como as TVs públicas "Rede Minas" e "TV Assembleia MG" têm incorporado e qualificado os cidadãos e como a recepção tem respondido a esses apelos através das redes sociais.

Palavras chave: Convergência; Televisão Pública; Redes Sociais; Segunda tela

SEGUNDA PANTALLA Y CONVERSACIONES EN LAS REDES SOCIALES: EL ANÁLISIS DEL COMPORTAMIENTO DE LAS TVS PÚBLICAS DE MINAS GERAIS

Resumen: Deseamos entender cómo es la dinámica de los procesos de comunicación y su flujo por estaciones públicas y sus usuarios; señalando a las interfaces creadas en el uso de la segunda pantalla. Los dispositivos móviles estimulan la acción para el análisis y el diálogo en este contexto de la convergencia y interacción entre televisión e internet las estaciones no pueden desconsiderar la presencia simultánea del telespectador en web. Palabras clave: convergencia; La televisión pública; redes sociales; segunda pantalla

SECOND SCREEN AND CONVERSATIONS IN NETWORKS: BEHAVIOR ANALYSIS OF PUBLIC TVS OF MINASGERAIS

Abstract: We want to understand how is the dynamics of communication processes and flow by public broadcasters and their users. Through analysis (in 2014 and 2016) we interpret how the public "Rede Minas" and "TV Assembleia MG" have built and qualified citizens and how the reception has responded to these calls through social networks.

Keywords: Convergence; Public Television; social networks; second screen 


\section{INTRODUÇÃO}

As ações na segunda tela² têm merecido discussões e atenções dos setores empresarial, tecnológico e comunicacional. Estabelecer um fluxo comunicacional efetivo nas redes sociais pelas emissoras televisivas públicas - com consequências na sua programação - é um dos desafios da contemporaneidade para este segmento. Com a digitalização da TV e com as novas possibilidades do ambiente convergente, a audiência passa a ter canais a ela disponíveis para se colocar ou até mesmo interferir na programação.

A essência da TV pública é de ser livre da sanção do mercado, livre da pressão por lucros. Como se diz, não precisa entrar na guerra de audiência e correr atrás do patrocínio, vendendo os espações entre a programação para a publicidade. Podemos nos questionar porque uma TV pública precisa entrar nestes novos ambientes e plataformas digitais denominados de redes sociais digitais, seja propagandeando seus produtos, seja produzindo conteúdo para esta plataforma, já que sua vocação não é para buscar a audiência como forma de gerar orçamento para sua manutenção. Não perseguir o lucro define o papel das TVs públicas quanto à dinâmica produtiva, de distribuição, de produção, de armazenamento da sua própria produção e memória. Mas, por outro lado a ocupação paulatina das TVs públicas no ambiente fluido do ciberespaço diz muito sobre nossa sociedade e sobre o modo de atuação enquanto consumidores de sites de redes sociais e enquanto cidadãos, quando falamos de emissoras com público.

Em 2014 monitoramos postagens e perfis nas redes sociais das emissoras TV Assembleia MGeRede Minas (FERREIRA, 2014). Em 2016, retornamos ao monitoramento das mesmas emissoras para verificar o fluxo tanto das emissoras como dos usuários-telespectadores. Notamos, já em análise superficial, o crescimento da atuação das organizações no ambiente digital. O maior número de seguidores nas redes para as duas emissoras também chama atenção já em um primeiro momento.

O ato de o espectador sentar no sofá, ligar a televisão, escolher o canal

2 Segunda Tela (ou Second Screen) é um termo que se refere a um dispositivo eletrônico adicional (como um smartphone ou tablet) que permite ao consumidor interagir com o conteúdo que está a consumir, como filmes, música ou jogos eletrônicos. Dados adicionais são exibidos no dispositivo portável sincronizados com as informações sendo mostradas na televisão.(fonte:https://pt.wikipedia.org/wiki/Segunda_tela. Acesso em 6 jun.2016)

Rev. Cad.Comun, Santa Maria, v.20,n.1, art 1, p.1 de 24, jan/abr.2016 
que passa o seu programa favorito, pegar o celular e começar a comentar o que assiste com quem bem entender através das redes sociais é cada vez mais o gesto e ação do telespectador no Brasil e no resto do mundo ao assistir um programa. ${ }^{3}$ Este comportamento, além de mudanças no aspecto social, também acarreta alterações no modo como o telespectador avalia o que consome. McLuhan, grande visionário, já tinha profetizado que os meios seriam extensões do homem. O meio é a mensagem (MCLUHAN, 1974). De fato, quando estamos no ambiente do ciberespaço estamos em comutação, estendemos nossos sentidos e nossas ações ao acionarmos a segunda tela. Mesmo não tendo como foco o crescimento da audiência, como as TVs públicas poderiam ficar fora desta perspectiva, desta forma comunicativa?

Em “Alternativas a la televisión actual”, Tornero et al. (2007) apresentam parte do papel social da TV educativa-cultural, ou TV pública, ao dizer que "assim, a televisão educativa-cultural nos apresenta não só como um gênero de cadeias ou programas específicos, mas como orientação genérica com um conjunto de atributos, de valores" 4 . Sem visar o lucro como trabalho fim, a função da TV pública, ainda segundo o autor, é promover e construir cidadania democrática, através de incentivo à participação popular no desenvolvimento dos direitos do homem e na democracia; além de promover a riqueza e diversidade da cultura, oferecendo educação cultural ao difundir a arte e a ciência.

A segunda tela desconstrói a concepção de espectador como aquele que está no contraplano apenas assistindo, que absorve conteúdo que é exibido. Os dispositivos móveis estimulam a ação para a análise e diálogo. Ou pelo menos parecem estimular. O comentário de amigos, de estranhos, a repercussão nas mídias sociais, acaba tendo influência se alguém irá assistir a um programa ou não; seja porque gosta, porque não conhece, ou porque não gosta e vai ver para "trolar"s . Nesse contexto de con-

3 De acordo com o Relatório de Tendências de Consumo em TV e Vídeo de 2012, organizado pela ConsumerLab, laboratório de pesquisas de comportamento da Ericsson, $73 \%$ dos entrevistados brasileiros usam redes sociais semanalmente enquanto assistem à TV - um aumento de 25 pontos percentuais com relação a 2011.

4 Tradução livre do original.

5 Um troll, termo derivado do inglês trolling, é gíria da internet e designa uma pessoa cujo comportamento tende sistematicamente a desestabilizar uma discussão e a provocar e enfurecer as pessoas nela envolvidas (fonte: https://pt.wikipedia.org/wiki/

Rev. Cad.Comun, Santa Maria, v.20,n.1, art 1, p.1 de 24, jan/abr.2016 
vergência e interação entre televisão e internet, as emissoras não podem desconsiderar a presença simultânea do telespectador na web. Por isso, o uso de mecanismos de interação, como hashtags e o convite para que o espectador acesse o site e demais redes sociais da emissora deve existir para que as empresas se conectem com a atitude do público que o assiste. Como as TVs públicas, a saber a TV Assembleia MGe Rede Minas, tem respondido a estas conversações que se dão nos seus perfis? Quais temas têm sido? São conversações ativas, reativas? Como interferem naquilo que é ofertado pelo canal televisivo?

Em pesquisa anterior (FERREIRA, 2014), verificamos que os profissionais de comunicação que produzem as informações, repórteres e mesmo editores, já estão reconfigurando o modo de produzir, editar e armazenar os produtos que vão ao ar. Hoje os repórteres produzem matérias já com a preocupação de que o material coletado seja distribuído pelas redes sociais e plataformas multimídia. Por outro lado, as habilidades solicitadas para o exercício da profissão nas televisões têm alterado o perfil desde trabalhador, que tem que dominar diferentes tipos de linguagens processados pelos diferentes meios. A convergência de mídia requer produção de conteúdo diferenciado. As linguagens, mais do que nunca, para Férres (2014), devem trabalhar os aspectos multimodais de tal modo que haja sinergias tecnológicas, sensoriais e emocionais.

Como bem analisa Scolari (2009), ao falar da convergência e seus efeitos na área profissional, costumam ocorrer mudanças na hierarquização do trabalho jornalístico: cargos tradicionais deixam de existir, dando espaço a outros novos que despontam com a emergência das novas tecnologias incorporadas pelas TVs. Scolaritrata da questão de forma abrangente, sem circunscrevê-la ao âmbito televisivo, mas o detalhamento feito por ele se insere no que diz respeito aos impactos sentidos pela TV a partir da convergência:

O que está acontecendo nas redações dos meios informativos é representativo das transformações que toda indústria cultural está sofrendo. O desaparecimento de figuras profissionais tradicionais, o surgimento de perfis polivalentes, o desenvolvimento de novas rotinas produtivas e a entrada prepotente das tecnologias dentro das redações são só alguns dos elementos que mar-

Troll_(internet). Acesso em 6 jun.2016)

Rev. Cad.Comun, Santa Maria, v.20,n.1, art 1, p.1 de 24, jan/abr.2016 
Não só uma reestruturação no tocante à criação/eliminação de cargos, mas na própria organização do processamento do trabalho, porque evidentemente a não-linearidade proporcionada pelo sistema digital interfere no conteúdo produzido, bem como no tratamento desse conteúdo e quem diretamente vai lidar com ele.

Um conceito tratado por Scolari (2009) é o de verticalização do profissional, uma vez em que este assume maior responsabilidade sobre o conteúdo produzido além de protagonizar todo o processo produtivo da informação (não-linearidade). Com isso, o jornalista (no caso específico da televisão) passa a se pluralizar durante a produção e participar de etapas distintas da mesma. Além disto, ele deve estar preparado para atuar nas redes sociais. Exemplo disto é o grande número de postagens nos perfis das emissoras realizadas e assinadas pelos próprios profissionais das televisões.

Apesar das considerações sobre as transformações televisivas em face à digitalização do acervo e convergência de funções, o sistema econômico que mantém as emissoras em andamento teme os impactos que tal transitoriedade pode causar. Fazendo-se uso de um excerto de Salaverría (2003), ele anuncia a imprecisão que ainda paira sobre o futuro da comunicação justamente por estar submetida à transitoriedade gerada pela tecnologia tanto da parte dos editores como dos jornalistas.

A consequência de se implantar formas inovadoras na produção televisual repercute diretamente na audiência e no modo como ela se comporta diante de tais alterações. Analisar a convergência apenas do âmbito tecnológico, não permitiria apreender vertentes de extrema significância - como os efeitos em curto prazo no público e nos produtores de conteúdo. Assim sendo, a TV potencializa ações sobre a sociedade como um todo - desde produtores até receptores de informações.

O que de fato se evidencia é a necessidade da TV se reconfigurar de forma a atender às novas demandas sociais. Para tanto, ela se insere na era das linguagens líquidas - na qual não há estabilidade e engessamento, como era característico em outros momentos da história da comunicação. A linguagem deixa de ser circunscrita e ganha uma dimensão espacial am-

6 Tradução livre do original

Rev. Cad.Comun, Santa Maria, v.20,n.1, art 1, p.1 de 24, jan/abr.2016 
pliada.

Os laços sociais na contemporaneidade têm sido redimensionados a partir do uso da segunda tela. Conforme nos mostra Lemos, o fluxo no Facebook, por exemplo, é muito mais suscetível de propiciar laço social que nas outras redes, já que no Facebook

Existe a possibilidade de formação de grupos ao redor de interesses compartilhados, a tônica da interação continua sendo o vínculo pessoal preexistente na história afetiva e/ou profissional de cada um. (LEMOS, 2010, p. 91)

Lemos observa também que no Twitter os laços sociais não estão baseados em vínculos preexistentes, mas sim "na penetração individual em fluxos de ideias, ou seja, fluxos coletivos abertos de ideias compartilhadas em tempo real, que estão em movimento contínuo" (LEMOS, 2010, p. 91).

O processo citado acima e as duas fases de monitoramento exemplificam de modo cabal e diacrônico o processo evolutivo da tecnologia em concomitância com a evolução da TV- geralista, da TV, digamos, tradicional, de massa, popular. De fato, mostram o papel relevante que o processamento técnico tem hoje na composição de ideias e costumes.

Em termos de televisão, o telespectador utiliza recursos da rede (blogs, sites, e-mails, perfis em redes sociais) para se mostrar como uma voz que busca aparecer e ter destaque. $O$ espaço dado a vozes distintas e diversas cria um dialogismo do público com a TV e do público com o próprio público. Isso ocorre a partir do momento em que a TV abre-se para os canais interativos e para a hiperconexão que, acreditamos, acaba propiciando laços sociais se a comunicação se efetiva de fato.

Nesta tendência pós-network, Fechine (2009, p. 139) expõe de maneira clara quais devem ser os parâmetros de reflexões referentes à televisão em dias de convergência. Para ela, o sistema de circulação e de distribuição de conteúdo ganha relevo em relação nos meios interativos. Seguindo ainda os preceitos de Fechine, estabelecer uma relação entre destinatários e destinadores a partir do espaço cibernético obriga a TV a se reestruturar conforme as diretrizes temporais impostas pela rede. Se a audiência encontra na rede com extrema facilidade os conteúdos televisivos que lhe agradam, preciso é buscar alternativas para conquistar públicos mais jovens, já habituados a um sistema comunicacional de colaboração e interação social mediada por computador. A instantaneidade da rede estimula

Rev. Cad.Comun, Santa Maria, v.20,n.1, art 1, p.1 de 24, jan/abr.2016 
a TV a cada vez mais investir no uso do ao vivo para expressar a noção de alcance absoluto dos fatos a qualquer momento.

Em um processo dessa natureza, a própria linguagem se modifica com a inserção de novas tecnologias no processo de produção e recepção da notícia. A mídia televisiva se reorganiza e acaba também reorganizando a sociedade em dadas proporções. Atualmente, essa organização deve ser analisada sob o aspecto da convergência tecnológica, porque é justamente isso que vem ditando o processo produtivo. Não é possível ater-se a um estilo tradicional de produção da notícia, numa época em que a tecnologia ascende sobremaneira, uma vez que a inserção de meios digitais de comunicação agrega à televisão tradicional outras vias de se aproximar do público e concomitantemente dar-lhe espaço, de expandir-se.

\section{OBJETIVOS DE PESQUISA}

Independentemente do regime público ou privado e diante da fecundidade e potencialidade da tecnologia cabe nos indagarmos sobre as ações que as TVs públicas têm feito nas redes sociais e como os se desenha as ações dos usuários num espaço de quase dois anos.

A pesquisa aborda como as TVs regionais públicas - Rede Minas e TV Assembleia MG - têm usado as redes sociais não só para manter a audiência, mas para começar a criar um canal de interação e de interatividade com seus espectadores neste novo ambiente denominado de redes sociais, propiciado pelo ciberespaço. Buscamos detectar as transformações que vem se operando neste ambiente e fluxo comunicacional dado através da segunda tela.

Buscamos compreender como a cultura midiática inscreve traços culturais dentro da própria cultura televisiva através das redes sociais. Enfim como se dá a fluição das emissoras e dos usuários nesse fluxo comunicacional. Até que ponto este momento conceitualmente identificado como sendo pós-televisivo, pós-network é realidade na TV regional que atravessa um momento de transição do analógico ao digital em tempos de convergência?

\section{METODOLOGIA DE MONITORAMENTO}

Para examinar a maneira como as emissoras TV Assembleia MG e Rede Rev. Cad.Comun, Santa Maria, v.20,n.1, art 1, p.1 de 24, jan/abr.2016 
Minas atuam nas redes sociais e para dimensionar a interação entre espectador e emissora no cenário da convergência midiática, realizamos um monitoramento dos perfis das emissoras nas redes sociais. O monitoramento inicial foi realizado do dia $1^{\circ}$ ao dia 31 de maio de 2014 e o segundo monitoramento do dia 22 a 28 de fevereiro de 2016, ambos por meio de uma plataforma de monitoramento e análise de mídia, chamada Opsocial ${ }^{7}$

Determinamos termos de monitoramento para cada emissora. Essas palavras-chave filtram o tipo de conteúdo a ser catalisado pela plataforma e mostram a quantidade de vezes que tais termos apareceram nas redes sociais.Selecionamos os termos de monitoramento após análise manual das publicações das emissoras. Constatamos que os termos e expressões mais frequentes nas redes sociais das organizações em questão, utilizados tanto em postagens da própria rede quanto em conteúdos publicados pelos internautas, são: REDE MINAS e @redeminaseTV Assembleia MG e @ tvalmg.

Para qualificar as postagens a plataforma Opsocial oferece ao usuário as opções: positivo, neutro e negativo.Tais opções nos permitiram classificar as publicações e tweets quanto à relação de sentimento do usuário para com aquele conteúdo (posteriormente denominada como análise de sentimento). Com a intenção de padronizar essa classificação foi definido que tipo de conteúdo seria aceito em cada categoria:

? Positivo: compartilhamento e retweets de conteúdos relacionados à emissora ou sua programação, sugestões de pauta, elogios à emissora ou a sua programação.

? Neutro: posts com dúvidas, que não são relevantes para o conteúdo da emissora, ou relacionados à vida pessoal de personagens da emissora (apresentadores/funcionários).

? Negativo: reclamações e críticas pejorativas, descontrutivas sobre conteúdo ou programação.

Para obter dados qualitativos em relação às postagens, além dos termos de monitoramento, estabelecemos, especificamente, 10 Tags - nesse caso entende-se a palavra tag como um comando de classificação - que nos auxiliaram na tabulação do tipo de atividade da emissora e do usuário nas redes sociais, além de nos permitir gerar uma análise quantitativa des- 
sa atividade. São elas:

1. Críticas à programação: comentários giram em torno de novos programas inseridos, ou alterações nos programas já existentes.

2. Críticas à emissora: críticas diretas e gerais à emissora enquanto promotora de conteúdo. Críticas aos programas da grade, aos temas das matérias, à grade de programação, à postura da emissora em relação a determinados assuntos.

3. Sugestão de pautas: ideias sobre assuntos a serem tratados, inclusive com apresentação de fontes e outros materiais como fotos, que poderão colaborar na elaboração da matéria.

4. Denúncias: reclamações contra serviços públicos, flagras fotográficos de crimes de todo gênero, sugestões de investigação sobre determinado assunto. Neste caso, também há presença de material que poderá colaborar na produção da matéria, como fotos flagrantes.

5. Elogios à programação: comentários giram em torno de novos programas inseridos, ou alterações nos programas já existentes.

6. Elogios à emissora: elogios diretos e gerais à emissora enquanto promotora de conteúdo. Elogios aos programas da grade, aos temas das matérias, à grade de programação.

7. Repercussão de posts da emissora: compartilhamento e retweets de conteúdos postados pela emissora ou relacionados à emissora e sua programação.

8. Dúvidas sobre matérias, programação, etc.: dúvidas de toda natureza, como horários de programas, se haverá reprises, dúvidas sobre temas tratados nas matérias.

9. Sobre o assunto: comentários acrescentando alguma curiosidade sobre o tema abordado nas matérias. Há comentários imparciais, críticas negativas a algo apresentado na matéria e não exatamente à emissora, e da mesma forma elogios.

10. Publicação por parte da emissora: conteúdo que a própria emissora publica para divulgar conteúdos relacionados à sua programação diária e posts de divulgação direta de conteúdo, por exemplo, vídeos de matérias da TV e programas que já foram exibidos na TV.

A plataforma de monitoramento também permite que sejam gerados relatórios com os dados coletados a partir das qualificações citadas acima. Esses relatórios são fundamentais para dimensionar a relação entre espectador e emissora. Neles é possível identificar dados numéricos rela-

Rev. Cad.Comun, Santa Maria, v.20,n.1, art 1, p.1 de 24, jan/abr.2016 
tivos à ação das organizações nas redes sociais - a quantidade de posts do período; em qual rede social a emissora é mais atuante; o horário e o dia da semana em que houve o maior número de posts; entre outros.

\section{ANÁLISE}

O monitoramento realizado em 2014, através da plataforma Opsocial, foi mais extenso devido ao acesso ilimitado aos dados das redes sociais. Atualmente, o Facebook, por exemplo, não permite que aplicações externas, como a Opsocial, acessem dados gerados dentro da rede, como engajamento, participação, número de publicações ou perfil social informado dos usuários. Portanto, a Opsocial gerou dados relativos às redes sociais citadas mais a frente, e os dados referentes à rede social Facebook aqui apresentados, foram recolhidos manualmente, no mesmo período de monitoramento via plataforma.

O resultado quantitativo frio (o volume de publicações, comentários, retweets, etc) se alterou nos dois monitoramentos realizados por conta de a plataforma disponibilizar, em versão anterior, maior período contínuo de análise. Apesar de que, se tratando de análise diferencial, o que nos importa e deve ser considerado é o cálculo de porcentagem, que foi realizado com mesma precisão nos dois momentos.

Com base nos dados recolhidos em 2014 e na segunda edição do monitoramento, em 2016, foi possível perceber diferenças significativas de atuação nas redes sociais. As observações que se seguem foram baseadas em parte dos dados gerados por esse período de monitoramento.

\subsection{Rede Minas}

A emissora Rede Minas,em 2014, possuía 4 perfis ativos em redes sociais distintas: Facebook, Twitter, Google+ e Youtube. Atualmente, a emissora ainda está presente em 4 redes sociais distintas, porém, não se encontra mais o perfil no Google+ (que já era inexpressivo na pesquisa anterior). Em janeiro de 2016, a TV Rede Minas passa a ser atuante também no Instagram. Os links para os perfis da emissora podem ser encontrados no próprio site institucional: http://redeminas.tv/.

A rede social com mais participação dos usuários continua sendo, com uma discrepância muito grande, o Facebook. A tabela 1 apresenta o alcan-

Rev. Cad.Comun, Santa Maria, v.20,n.1, art 1, p.1 de 24, jan/abr.2016 
ce da Rede Minas nas redes sociais em ambas as pesquisas:

\begin{tabular}{|c|c|c|c|}
\hline REDE[MINAS & \multicolumn{3}{|c|}{ Rede Minas } \\
\hline Rede Social & Facebook & Twitter & Youtube \\
\hline $\begin{array}{c}\text { Alcance } \\
2014\end{array}$ & 50.000 curtidas & 20,6 mil seguidores & 1.766 inscritos \\
\hline $\begin{array}{c}\text { Alcance } \\
2016\end{array}$ & 64.180 curtidas & 1.555 seguidores? & 2.777 inscritos \\
\hline
\end{tabular}

Tabela 1 - Dados comparativos redes sociais Rede Minas

Fonte: Ferreira, 2014 e coleta manual em 09/05/2016

O dia e horário predominante de publicações se alterou consideravelmente, mudando o intervalo de 17-18h às sextas, para 22-23h às segundas. O horário com maior volume de posts encontrados em 2014(entre 17h e $18 \mathrm{~h}$ ), que registrou $10 \%$ das postagens (figura 1), antecedia a exibição da $2^{a}$ edição do Jornal Minas, que permanece na grade de programação da emissorade segunda a sexta às 19h30. Já o gráfico de postagens analisado em 2016 (figura 2), revelou que o intervalo das $22 \mathrm{~h}$ às $23 \mathrm{~h}$ acumula $25 \%$ das publicações. Não coincidentemente, na segunda feira (que foi o dia predominante na análise 2016 - com $24 \%$ dos posts concentrados neste dia) neste exato horário das $22 \mathrm{~h}$ é veiculado o programa Roda Viva, notadamente, um destaque em conteúdo e produção da emissora. 


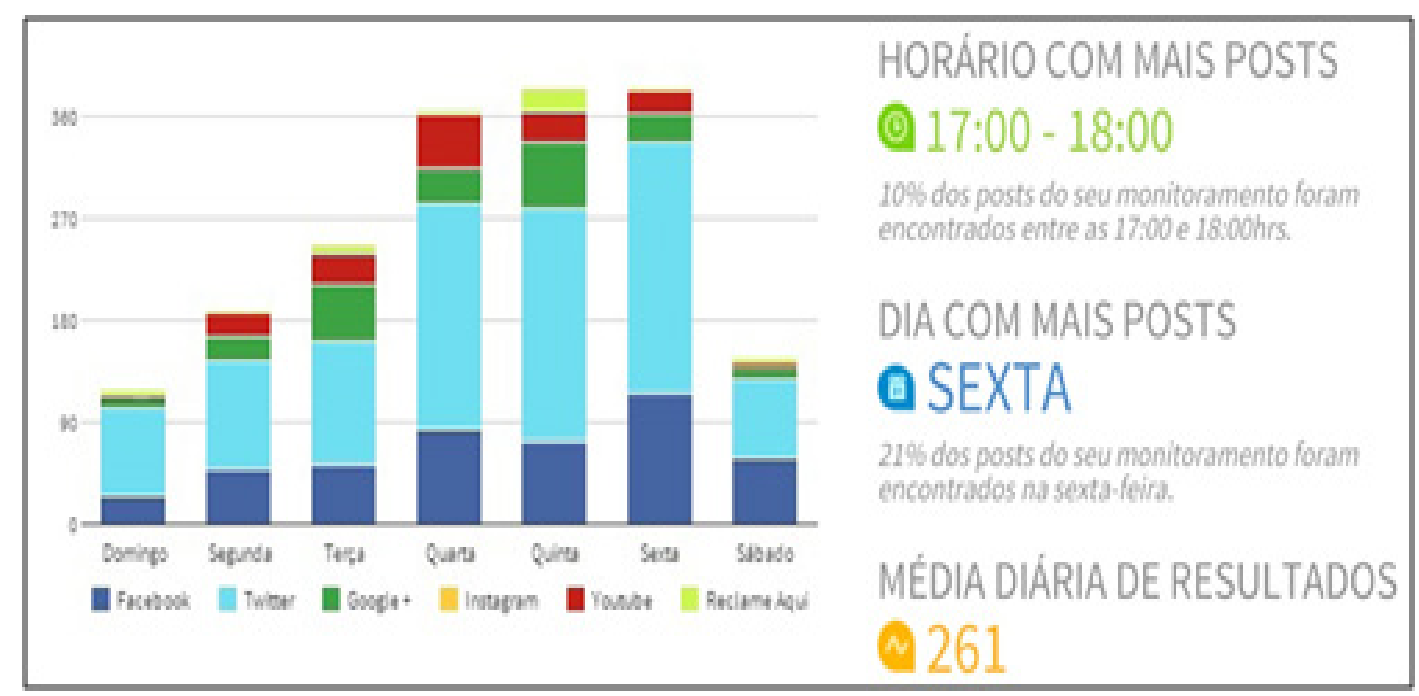

Figura 1-Gráfico com os dias e horários mais atuantes da Rede Minas Fonte: Reprodução do relatório OpSocial 2014

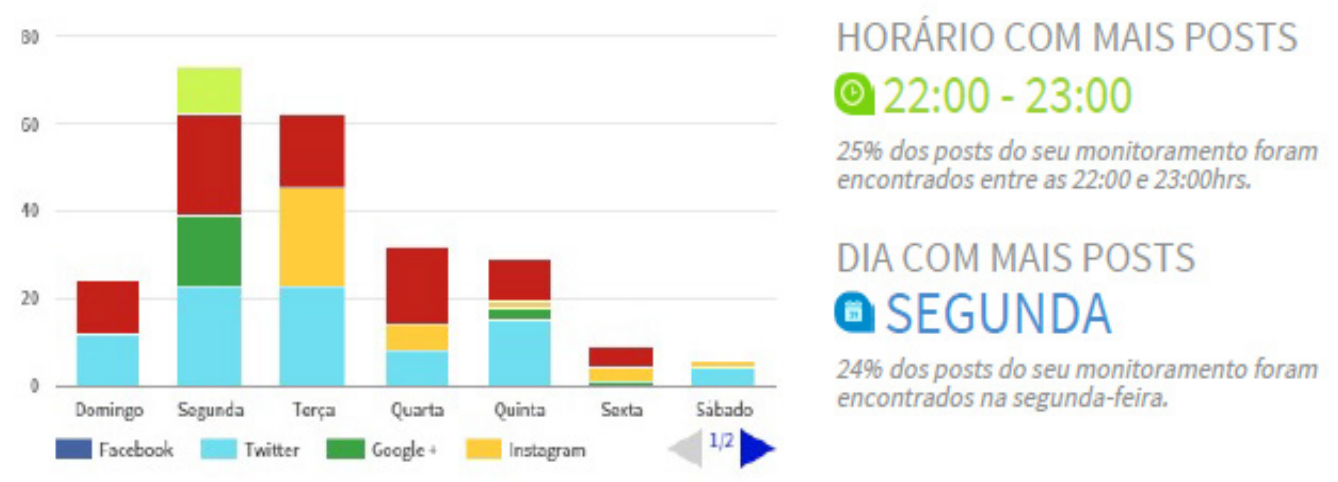

Figura2 -Gráfico com os dias e horários mais atuantes da Rede Minas Fonte:Reprodução do relatório OpSocial 2016

A análise de sentimento realizada em 2016 (figura 4), ainda mostra como predominante a reação positiva às publicações e conteúdo da TV Rede Minas. Porém, em comparação com a análise de sentimento de 2014 (figura 3), percebe-se que o número de reações neutras e negativas aumentou. O monitoramento, por parte da emissora, do sentimento dos usuários, aliado à análise do conteúdo dessas manifestações, permite gerar um ‘termômetro indireto' (não oficial) sobre a programação da emissora. O sentimento identificado com a análise completa da reação do público em determinado período soa mais espontâneo e natural do que as opiniões transmitidas através de uma reclamação direta nos canais de comunicação da empresa (fale conosco, direct message, inbox ou email), que

Rev. Cad.Comun, Santa Maria, v.20,n.1, art 1, p.1 de 24, jan/abr.2016 
não refletem o comportamento e opinião da massa, mas sim do usuário individualmente (ou de seu grupo de relacionamento específico).
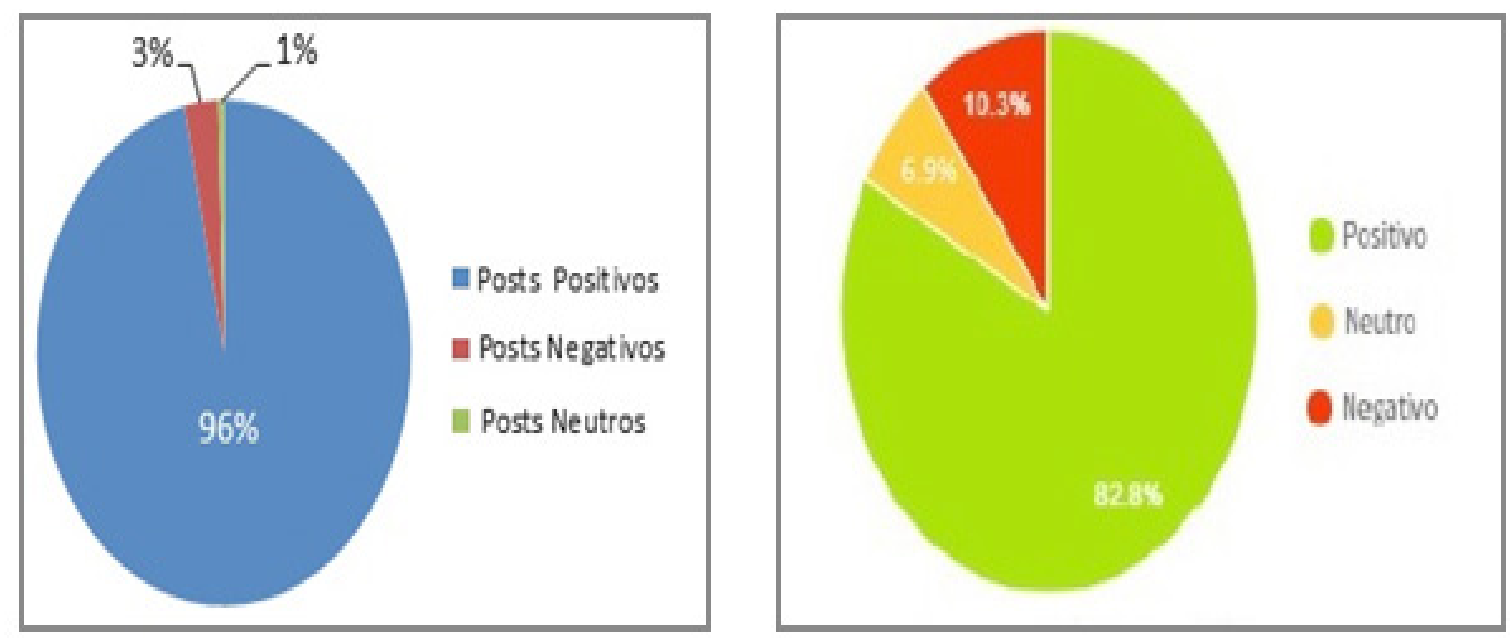

Figura 3 - Análise de sentimento 2014

Fonte: Ferreira, 2014

Figura 4 - Análise de sentimento 2016

Fonte: Relatório OpSocial 2016

No Facebook, a atuação da Rede Minas ainda é bem precária e não oferece comunicação ativa com os usuários. Não há incentivo à interatividade e a emissora não se preocupa em responder os poucos comentários que surgem em suas publicações. Interessante ressaltar que há uma subdivisão da divulgação dos programas da Rede Minas, havendo uma página central e principal - denominada "Rede Minas" - e outras páginas específicas para os programas fixos da emissora - a página "Programa Agenda", por exemplo, existe desde 2012; já a página "Programa Mulhere-se", criado recentemente, surgiu esse ano. Essas páginas secundárias produzem conteúdoexclusivamente referente aos programas homônimos. O perfil principal da Rede Minas compartilha esses conteúdos convidando o usuário a seguir a programação.

De uma maneira geral a atuação da Rede Minas nas redes sociais é positiva levando em consideração o monitoramento e a produção gráfica de seus perfis. Porém, em relação ao alcance da emissora na web, percebemos algo semelhante ao percebido em 2014: baseado no número de seguidores das redes sociais, sua atuação e a resposta dos usuários poderiam ser muito mais efetivas se houvesse um gerenciamento específico voltado para as redes sociais.

Rev. Cad.Comun, Santa Maria, v.20,n.1, art 1, p.1 de 24, jan/abr.2016 
Através da classificação por tags (descritas na metodologia), foi possível traçar o perfil das atividades dos usuários nas redes sociais da Rede Minas. Todos os posts qualificados para análise de sentimento foram também marcados com uma ou maistags que descreviam a que tipo de ação aquela postagem estava relacionada.

A partir dessa análise verificou-se que a principal forma de interação entre emissora e usuário deixou de ser por meio da repercussão de posts da emissora- que em 2014 representava 51\% das publicações e agora representa apenas $25,7 \%$. Se antes o usuário se mostrava presente através do compartilhamento e retweets de conteúdos postados pela própria emissora, relacionados à sua programação, agora ele se manifesta predominantemente com comentários referentes às postagens. Em análise anterior, a tagsobre o assunto respondeu por apenas 0,5\% das atividades do usuário nas redes sociais, e, atualmente, corresponde à maioria das manifestações, aumentando assim a proporção de pessoas que não só compartilham e retuitam, mas que comentam. O usuário deixou de ser passivo e se tornou ativo no processo de compartilhamento de conteúdo gerado pela emissora.

A porcentagem de publicação por parte da emissora caiu drasticamente, mostrando o que já havíamos alertado em 2014: a Rede Minas é passiva em sua própria divulgação (de 32\%, caiu em 2016 para 6,9\%). Apesar de a porcentagem de publicações da emissora ter caído, a participação dos usuários (relativa à tag "sobre o assunto) aumentou, o que demonstra que é mais interessante para o usuário conteúdo relevante do que um grande volume de publicações.

Vindo ao encontro do que já elucidamos nas considerações sobre análise de sentimento, percebemos que a tag críticas à emissora - com valor de 1,4\% em 2014, representa agora 11,9\% das manifestações. A tag elogios à emissora, porsua vez, não apresentou nenhum post relacionado, caindo de $5 \%$ para $0 \%$. No que se refere a programação, a tag elogios à programação representou 6\% das postagens em 2014, e agora assume $2 \%$, e a tag de críticas à programação subiu de $0,8 \%$ do total para $4,9 \%$. Os dados de críticas à programação podem ter aumentado significativamente por conta do momento político conturbado que vivemos. Eventualmente Rede Minas trata de assuntos polêmicos e acaba despertando a 'fúria' de quem não concorda com o assunto ou posicionamento apresentado.

Vale ressaltar que a grande maioria dos seguidores não fez qualquer

Rev. Cad.Comun, Santa Maria, v.20,n.1, art 1, p.1 de 24, jan/abr.2016 
tipo de avaliação dos conteúdos publicados pela emissora. Outros dados que reforçam esse comportamento são os das tags dúvidas sobre matérias e programação e sugestão de pauta que em 2014 apresentaram resultados nulos e, em segundo momento, ainda com resultados tímidos, permanecem inexpressivas. A tag de denúncias,que correspondeu a 3,5\% das publicações, também se mostrou nula em segunda análise, o que reforça ainda mais, a falta de interesse por parte do usuário e a falta de incentivo por parte da emissora para participação. Um comparativo do comportamento do usuário pode ser observado na tabela 2, apresentada a seguir:

\begin{tabular}{l|c|c|}
\multicolumn{1}{c|}{ Tags } & $2014^{*}$ & $2016^{*}$ \\
\hline Críticas à emissora & $1,4 \%$ & $11,9 \%$ \\
\hline Críticas à programação & $0,8 \%$ & $4,9 \%$ \\
\hline Denúncias & $3,5 \%$ & - \\
\hline Dúvidas sobre matérias e programação & - & $1 \%$ \\
\hline Elogias à emissora & $5 \%$ & - \\
\hline Elogios à programação & $6 \%$ & $2 \%$ \\
\hline Publicação por parte da emissora & $32 \%$ & $6,9 \%$ \\
\hline Repercussão de posts da emissora & $51 \%$ & $25,7 \%$ \\
\hline Sobre o assunto & $0,5 \%$ & $46,5 \%$ \\
\hline Sugestão de pautas & - & $1 \%$ \\
\hline
\end{tabular}

Tabela 2 -Comparativo comportamento usuários (*valores aproximados) Fonte: Ferreira, 2014 e relatório OpSocial 2016

Rev. Cad.Comun, Santa Maria, v.20,n.1, art 1, p.1 de 24, jan/abr.2016 


\subsection{TV Assembleia MG}

A emissora TV Assembleia MG, em 2014 não se encontrava atuante nas quatro redes sociais analisadas, possuindo apenas perfil no Google+e no Youtube. Atualmente, a presença já é mais expressiva, mas ainda muito longe do ideal. Em 2016, a TV Assembleia MGpermanece com canal no Youtube e perfil no Google+ (sem atualização desde out/2015), e aderiu ao Twitter e Instagram. A TV Assembleia ainda não possui perfil na rede social Facebook . A emissora não tem site com domínio institucional próprio, sendo que o link para acesso à área exclusiva da TV é referente ao site da Assembleia Legislativa de Minas Gerais, http://www.almg.gov.br/acompanhe/tv_assembleia/. No endereço há o redirecionamento para redes sociais da Assembleia, que se misturam o tempo todo com referências à TV. Apenas o Twitter é rigorosamente separado do domínio da Assembleia Legislativa e possui conteúdo exclusivo e dedicado à programação da TV. Segue na tabela 03 a representação dos dados da TV Assembleia MG:

\begin{tabular}{|c|c|c|c|}
\hline $\begin{array}{c}\text { TV } \\
\text { Assemblea }\end{array} /$ TV Assembleia MG \\
\hline Rede Social & Facebook & Twitter & Youtube \\
\hline $\begin{array}{c}\text { Alcance } \\
2014\end{array}$ & Não possui & Não possui & 822 inscritos \\
\hline $\begin{array}{c}\text { Alcance } \\
2016\end{array}$ & Não possui & 4.763 seguidores & 1.832 inscritos \\
\hline
\end{tabular}

Tabela 3 - Dados comparativos redes sociais TV Assembleia MG Fonte: Ferreira, 2014 e coleta manual em 09/05/2016

Em 2014, foi detectado que o horário com maior volume de posts era $23 \mathrm{~h}$-0oh (28\% das postagens), nesse horário era exibido o programa "Sala de Imprensa", que atualmente está sendo veiculado às $18 \mathrm{~h}$, diariamente. Atualmente, o horário de pico de movimento é $22 \mathrm{~h}-23 \mathrm{~h}$, intervalo em que três programas são veiculados: Assembleia Notícia (factual), Mundo Político (entrevistas, comentários e notas sobre a movimentação política no

Rev. Cad.Comun, Santa Maria, v.20,n.1, art 1, p.1 de 24, jan/abr.2016 
CADERNOS DE COMUNICAÇÃO

UNIVERSIDADE FEDERAL DE SANTA MARIA

país) e Assembleia Debate. Notadamente programas que tratam do cenário político atual e incentivam o pensamento crítico sobre o momento que estamos vivendo.

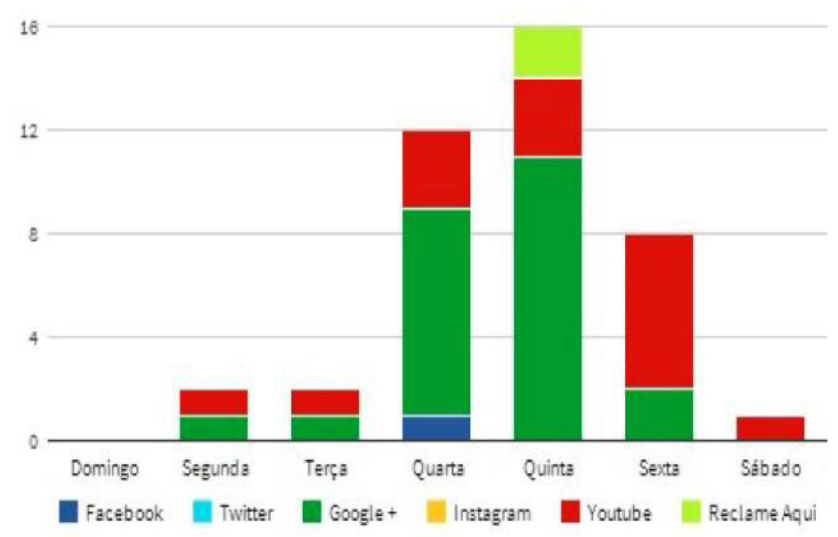

HORÁRIO COM MAIS POSTS

(ㅇ) 23:00 - 00:00

$28 \%$ dos posts do seu monitoramento foram encontrados entre as 23:00 e 00:00hrs.

DIA COM MAIS POSTS : QUINTA

$39 \%$ dos posts do seu monitoramento foram encontrados na quinta-feira.

MÉDIA DIÁRIA DE RESULTADO

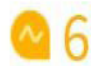

Figura 5-Gráfico com os dias e horários mais atuantes da TV Assembleia MG Fonte: Ferreira, 2014

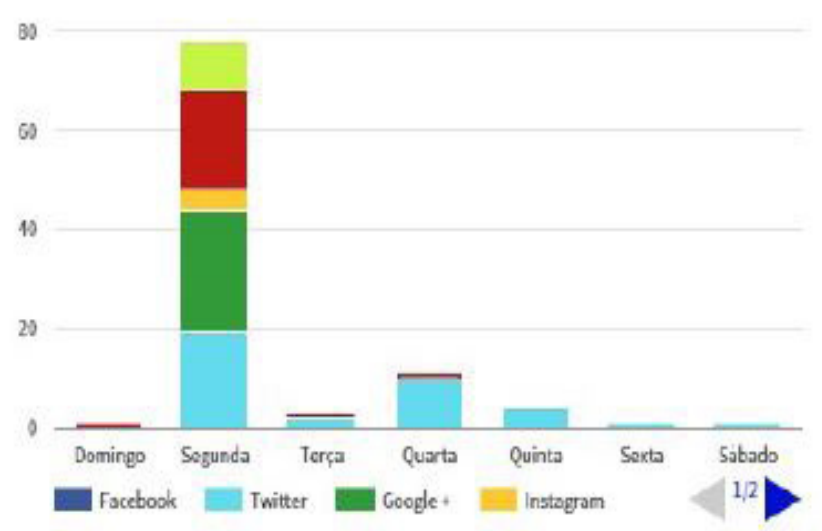
HORÁRIO COM MAIS POSTS (ㄱ) 22:00 - 23:00 $55 \%$ dos posts do seu monitoramento foram encontrados entre as 22:00 e 23:00hrs.

\section{DIACOM MAIS POSTS} @ SEGUNDA

$67 \%$ dos posts do seu monitoramento foram encontrados na segunda-feira.

Figura 6-Gráfico com os dias e horários mais atuantes da TV Assembleia MG Fonte: reprodução relatório OpSocial 2016

As análises de sentimento, apesar de realizadas com quase dois anos de diferença, apresentam uma mesma porcentagem de sentimento negativo: $0 \%$. Ambas as análises apresentaram alta porcentagem de sentimento positivo, sendo que a de 2016 quase alcançou 100\%, conforme percebido nas figuras 7 e 8 .

Rev. Cad.Comun, Santa Maria, v.20,n.1, art 1, p.1 de 24, jan/abr.2016 

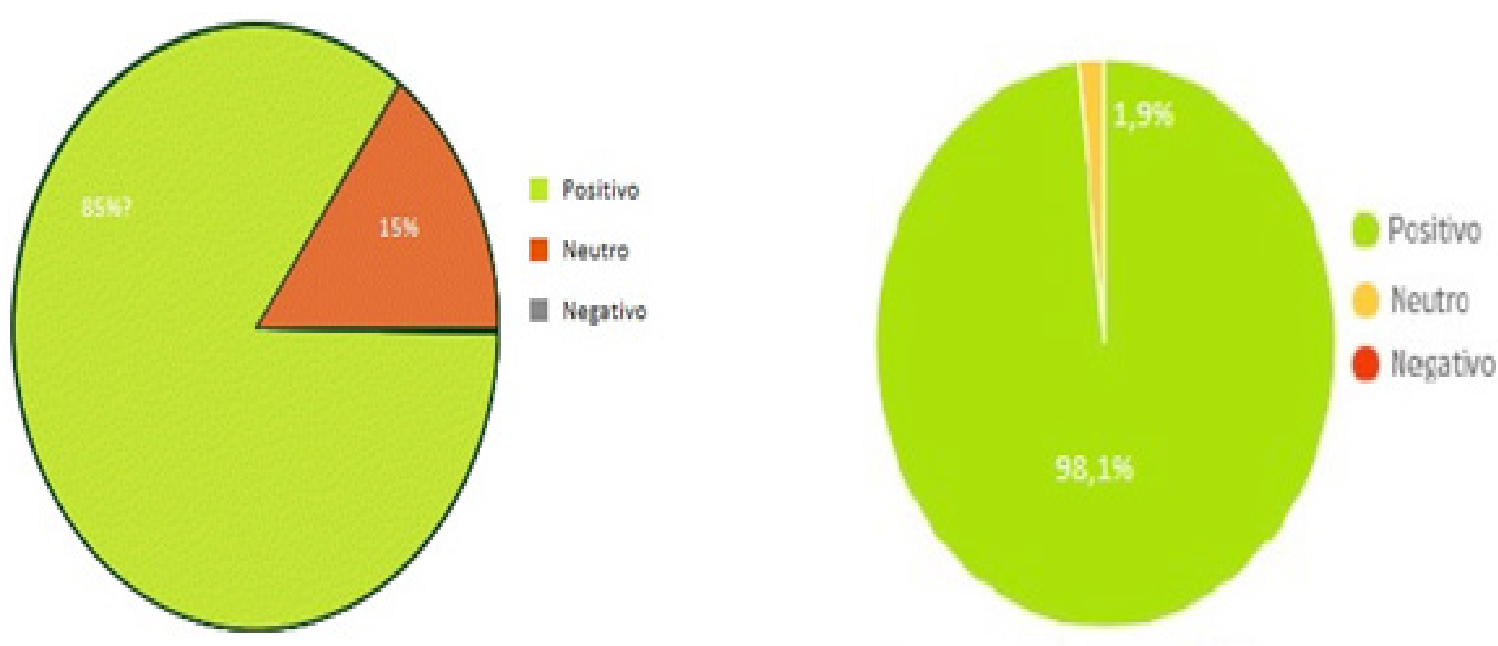

Figura 7 - Análise de sentimento 2014

Fonte: Ferreira, 2014

Figura 7 - Análise de sentimento 2016

Fonte: relatório OpSocial 2016

Apesar do resultado positivo da análise de sentimento do público em relação a emissora (em 2014 e em 2016) não podemos considerar que a TV Assembleia tem uma atuação positiva nas redes sociais. O conteúdo gerado pela emissora no Twitter não agrega nenhum valor ao usuário; não há uso de hastags e nem incentivo à interatividade. Em nenhum momento as publicações do Twitter possuem algum link com os vídeos veiculados no Youtube, apesar de ambos (tweet e vídeo se relacionarem ao mesmo conteúdo, a própria programação da emissora. Comparando as análises de 2014 e 2016, vemos um aumento significativo na repercussão dos posts da emissora, que saltou de $30,5 \%$ para $70,8 \%$, indicando que mais pessoas compartilham o conteúdo postado pela emissora. A elevação das tags sobre o assunto (de $0 \%$ para 10,8\%), elogios à emissora (de $0 \%$ para 1,5\%) e críticas à programação (de $0 \%$ para 3,1\%) indicam que os temas tratados pela emissora têm atraído um pouco mais a atenção do público, talvez não ainda o suficiente.

As demais tags, que permaneceram zeradas (críticas à emissora, denúncias, dúvidas sobre programação, elogios à programação e sugestão de pautas) indicam uma falta de esforço da emissora para envolver o usuário e promover a interatividade. Como se vê nos dados da tabela 4: 


\begin{tabular}{|l|c|c|}
\hline \multicolumn{1}{|c|}{ Tağs } & $2014^{*}$ & $2016^{*}$ \\
\hline Críticas à emissora & - & - \\
\hline Críticas à programação & - & $3,1 \%$ \\
\hline Denúncias & - & - \\
\hline Dúvidas sobre matérias e programação & - & - \\
\hline Elogias à emissora & - & $1,5 \%$ \\
\hline Elogios à programação & - & - \\
\hline Publicação por parte da emissora & $69,5 \%$ & $13,9 \%$ \\
\hline Repercussão de posts da emissora & $30,5 \%$ & $70,8 \%$ \\
\hline Sobre o assunto & - & $10,8 \%$ \\
\hline Sugestão de pautas & - & - \\
\hline
\end{tabular}

Tabela 4 - Comparativo comportamento usuários (*valores aproximados) Fonte: Ferreira, 2014 e relatório OpSocial 2016

\section{CONSIDERAÇÕES FINAIS}

A organização da TV nos tempos de hoje já não reflete a composição à época de seu surgimento, assim como a TV daqui alguns anos não refletirá o estilo adotado atualmente. A convergência não é um processo simples e repentino a ser julgado por pesquisadores; ela se constitui numa longa forma de alteração da produtividade vigente para que a TV se encaixe no que hoje chamamos de ambiente de fluição midiática.

Analisando o que vemos atualmente como produção televisiva pelas redes locais, é cabível considerar a necessidade de reestruturação da televisão diante da internet e das novas ferramentas que com ela ganham espaço na sociedade hiperconectada. A TV pública, ao buscar cumprir o seu papel social, se vê obrigada a entrar no ambiente digital, mas segue ainda sendo intimidada pela onipresença das redes e dos usuários continuamente conectados. As redes públicas, assim como quaisquer outras, devem

Rev. Cad.Comun, Santa Maria, v.20,n.1, art 1, p.1 de 24, jan/abr.2016 
ver na internet uma oportunidade de expansão real, de uso consciente da segunda tela como, de fato, uma tela a mais para o usuário - com conteúdo diferenciado, atrativo e que gere valor. A web é, atualmente, um canal onde a promoção da cidadania e o convite à participação deve reger o posicionamento das TVs públicas, com vistas a combinar estratégias para fortalecimento do laço social e também para a realização de atuação mais plena do internauta.

As dinâmicas já se alteraram. Percebemos, conforme os dados nos mostram, que a evolução tem chegado. A passos - muito - lentos, mas a implementação está sendo feita. Ter profissionais exclusivamente dedicados a gerar conteúdo nas redes, incentivar e responder a interações demostra uma pré-disposição a incorporar a web como rotina produtiva das redações televisivas. Principalmente o recolhimento e a incorporação das sugestões dos usuários repercutiriam diretamente no conteúdo daquilo que é produzido e transmitido via televisão.

A TV comercial se movimenta de maneira mais rápida, conforme relaciona Ferreira (2014), ao mostrar as diferentes inserções de programas com tradição televisiva nos seus portais e redes sociais digitais online. Percebemos que as emissoras públicas não se isentaram do processo de convergência, mas ainda se posicionam com cautela quanto às mudanças culturais que já batem à porta, tanto do seu próprio lado, como do lado da audiência, ou seja, o processo colaborativo só se inicia. Os canais precisam apontar para mudanças mais eficazes que insira o internauta como sujeito participativo.

A audiência não é mais mera repercutidora de conteúdos da TV. A web clama por participação, bastam os ouvidos atentos das redes públicas para ouvi-la. Só através da interação e participação com a cultura da convergência será possível enfrentar o momento de transição e passar por ele sem sentir perdas gigantescas. Enquanto a televisão souber lidar produtivamente com a convergência, com as demais telas que se sobrepõem, terá conquistas a seu favor - independentemente do tempo que se leve para uma completa transição até a chegada desses benefícios.

Rev. Cad.Comun, Santa Maria, v.20,n.1, art 1, p.1 de 24, jan/abr.2016 
CADERNOS DE COMUNICAÇÃO

UNIVERSIDADE FEDERAL DE SANTA MARIA

\section{REFERÊNCIAS}

FECHINE, Yvana. A Programação da TV no cenário de digitalização dos meios: configurações que emergem dos reality shows. In: FILHO, José Freire. A TV em transição. Porto Alegre: Sulina, 2009.

FERREIRA, Soraya. A televisão em tempos de convergência. Editora UFJF: Juiz de Fora, 2014.

FERREIRA, Soraya. Modos de fluição do usuário no uso da segunda tela: Dinâmicas dos processos comunicacionais em emissoras brasileiras. Córdoba, Argentina: ALAIC 2015. $16 \mathrm{p}$.

FÉRRES, Joan i Pratis. Las Pantallas y el Cerebro Emocional.Barcelona: Gedisa.2014.

LEMOS, Renata et SANTAELLA, Lúcia. Redes Sociais Digitais a cognição conectiva do twitter. São Paulo: Paulus.2010.

MCLUHAN, Marshall. Os meios de comunicação como extensões do homem. São Paulo: Cultrix, 1974

MILLER, Toby. A televisão acabou. A televisão virou coisa do passado. A televisão já era”. In: FILHO, José Freire. A TV em transição. Porto Alegre: Sulina, 2009.

PRADO, José Luiz Aidar. Crítica das práticas midiáticas: da sociedade de massa às ciberculturas. São Paulo: hacker editores, 2002.

PRIMO, Alex. “Crítica da Cultura Da Convergência: participação ou cooptação?” In: DUARTE, Elizabeth Bastos e LILIA, Maria. Convergências Midiáticas: produção ficcional-RBS TV. Porto Alegre: Editora Sulina, 2010.

SALAVERRÍA, Ramón. "Convergência de médios”. Revista Latino-americana de Comunicassem Chasqui, 2003. Disponível em: http://chasqui.comunica.org/content/ view/190/64. Acesso em: 15/10/2011.

SANTAELLA, Lúcia Linguagens líquidas na era da mobilidade. São Paulo: Paulus, 2007. SCOLARI, Carlos. "Alrededor de La(s) convergencia(s). Conversaciones teóricas, divergências conceptuales y transformaciones nele ecosistema de médios". Signo y Pensamiento. Bogotá, vol. XXVIII, nº 54, pp. 44-55, 2009.

TORNERO, José Manuel Peréz et al. Alternativas a la televisión actual. Barcelona: Gedisa, 2007.304 p.

WOLTON, Dominique. Elogio do Grande Público. Rio de Janeiro: Editora Ática, 1996. 


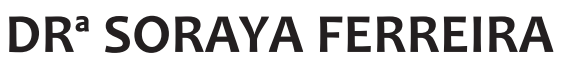

Professora da Universidade Federal de Juiz de Fora (UFJF), docente do PPGCOM (Programa de Pós-Graduação em Comunicação) - FACOM (Faculdade de Comunicação) da UFJF. Jornalista. Mestrado e doutorado na Pontifícia Universidade Católica de São Paulo (PUC-SP) no Programa de Pós-Graduação em Comunicação e Semiótica. Autora de "A Televisão em Tempos de Convergência” (2014). E-mail: sovferreira@gmail.com

\section{ISABELA NORTON}

Graduanda do $8^{\circ}$ período de Comunicação Social, com habilitação em Jornalismo, pela Universidade Federal de Juiz de Fora/MG. Experiência e ênfase em Social Media. Bolsista de Iniciação Cientifica - ProPesq, desenvolvendo atualmente a pesquisa intitulada "Modos de Fluição do Usuário no uso da Segunda Tela. Dinâmicas dos Processos Comunicacionais em Emissoras Regionais". E-mail: nortonisabela@ gmail.com

RECEBIDO EM: 11/05/2016

APROVADO PARA PUBLICAÇÃO: 25/05/2016 